\title{
E1 anarquismo en el movimiento obrero judio de Buenos Aires (1905-1909)
}

\author{
Javier Diaz ${ }^{1}$ \\ Universidad de Buenos Aires - javierdiazbuenosaires@hotmail.com
}

\section{Introducción}

En este artículo analizaremos la historia de los círculos anarquistas judios que actuaron en Buenos Aires durante el segundo lustro del siglo XX, tratando de poner de relieve la política que dirigieron hacia los trabajadores de su colectividad inmigrante y sus especificidades como parte del movimiento anarquista a la vez que del movimiento obrero judio. Para ello en primer lugar describiremos los rasgos generales de la inmigración judía proletaria a la Argentina. Luego abordaremos la génesis del movimiento obrero judio, repasando la formación de las primeras organizaciones sindicales y políticas. Seguidamente se examinará el vínculo entre la colectividad ashkenazi y el anarquismo, para proceder finalmente al estudio de los primeros círculos judios ácratas. Indagaremos de qué forma los distintos grupos construían su identidad de clase y étnica, poniendo de relieve las diferencias entre ellos y en sus relaciones con el nacionalismo judío (sionismo). A través de la vertiente libertaria, contribuimos a la reconstrucción histórica de la tradición política clasista e internacionalista.

\section{La inmigración obrera judia en Buenos Aires}

A principios del siglo XX, los obreros de Buenos Aires tenían un origen mayoritariamente migrante: provenientes de otros países u otras provincias, en general también eran nuevos en la vida urbana. Si, por esta doble circunstancia, los trabajadores, tomados en su conjunto, "vivian en un lugar extraño entre extraños" (Suriano, 2000: 294), los judíos aparecian "como extranjeros entre los extranjeros" (Bilsky, 1992: 40,

1. Con la colaboración como traductora de Raquel Kuhn.

(Archivos, año IV, $\mathrm{n}^{\circ}$ 8, marzo de 2016, pp. 119-140) 
trad. nuestra). Esta doble distancia de los judíos respecto de la sociedad porteña se originaba en rasgos como la lengua, costumbres y religión; entre los ashkenazim (judios originarios de Europa Central y Oriental) persistió a través de toda una cultura ídish porteña, expresada en periódicos, literatura, obras de teatro, negocios, barrios y organizaciones de todo tipo. El ídish era el idioma más extendido entre las masas judías.

Las tendencias generales que alteraron el carácter de clase de la inmigración masiva se verifican también en la de origen judio: si al principio la mayoría se volcaba hacia la colonización agrícola, las posibilidades de acceso a la propiedad o arriendo de la tierra fueron mermando hasta que, hacia 1890, los inmigrantes pasaron a nutrir principalmente a la población urbana y a la reciente clase obrera argentina (Falcón, 1984: 55). La inmigración judia adquirió masividad a partir de los pogroms de Kishinev y Gomel en 1903 y de la guerra ruso-japonesa, pero sobre todo en 1906, cuando se desató en el Imperio zarista la reacción política, la xenofobia antisemita y una nueva ola de pogroms.

En 1909 la colectividad judía de Buenos Aires alcanzó la cifra aproximada de 25 mil personas, el $2 \%$ de la población porteña; en su mayoría eran jóvenes, varones y solteros (Mirelman, 1988: 6, 229; Schiller, 2006: 40). Se trataba ya mayoritariamente de elementos proletarios (Bilsky, 1987: 43). Esta distinta extracción social se correspondia con un grado menor de religiosidad y una mayor adhesión a las ideas avanzadas.

Se trataba -en su mayoría- de un elemento distinto de los colonos. No estaba animado de su ideal de trabajo agrícola ni de su ortodoxia religiosa. Si profesaba ideas, eran de redención social (de todo el género humano y no específicamente de los judíos). Pero, obviamente, la mayoría anhelaba la prosperidad económica, el ascenso social y la seguridad personal. A diferencia de la inmigración judía del período anterior, sólo tibiamente adherian a su religión y algunos se desvinculaban de ella, engrosando las filas de los agnósticos y ateos. (Lewin, 1971: 153)

Para esta primera década ha sido señalado el predominio numérico, entre los judíos porteños, de los ashkenazim provenientes de Europa Oriental. La mayoria eran balmelojes (poseedores de un oficio), entre los cuales abundaban sastres y carpinteros. Lewin refiere que "en su primera etapa, estos inmigrantes -por lo general- fueron obreros calificados en la pequeña y mediana industria” (1971: 153). A diferencia de los demás judios, los que provenían de Europa Oriental "desarrollaron todo tipo de oficios manuales, en general poco calificados" (Bilsky, 1989: 30); "en su mayoría eran pobres y se empleaban como operarios" (Mirelman, 1988: 
47). Con respecto a las ramas industriales en las que ingresaron, Bilsky (1989: 31) señala:

Aunque bastante diversificado, el trabajo judío se refugió preferentemente en la confección (sastres, costureras, cortadores, planchadores, etc.) y en otras ramas del vestido (calzado, peletería, gorrería, fabricación de pilotos); también en la industria del mueble (carpinteros, ebanistas, ilustradores, etc.).

Por esta razón, también eran en su mayoría obreros manuales los primeros activistas judios (Bilsky, 1987: 34). Los ashkenazim se asentaron en un principio en la zona céntrica de la ciudad, pero luego sobre todo en el barrio de Once, que comenzó a formarse como "ghetto abierto" alrededor de 1907.

\section{El movimiento obrero judío porteño}

En 1905 comenzó la política de izquierda entre los judíos de Buenos Aires, la cual prolongaba la actividad desarrollada en Europa. Los primeros movimientos registrados corresponden al anarquismo: el 15 de febrero de 1905, La Protesta publicó en primera plana un manifiesto firmado por el Grupo de Obreros Rusos en el que éste se declaraba "anarquista comunista" y proclamaba como objetivo difundir las ideas libertarias entre los rusos. El breve texto, apoyándose en la Ley de Residencia para combatir frontalmente la imagen de la Argentina como una tierra de libertad, sintetizaba la visión que los anarquistas judios tenian de su nuevo hogar.

Sin libertad de palabra ni de imprenta y expuestos a ser expulsados en tres días de la República, a nosotros no nos parece haber cambiado de lugar. Creemos encontrarnos en la misma Rusia; pero así como alli hemos combatido por un ideal de justicia aquí sabremos combatir por la misma causa.

A fines de febrero de 1906 un grupo difundió un manifiesto en los centros obreros convocando a reuniones de "rusos", que lograron atraer a unos 25 trabajadores. Un agente se infiltró entre ellos y los espió durante más de un mes, siendo informado por sus empleadores acerca de quiénes observaban "buena conducta" y quiénes no. En marzo fueron detenidos 18 asambleístas, entre ellos Benjamín Israel, José Yavich ${ }^{2}$ y Antonio Sarkosky. El último confesó ser anarquista, aunque al parecer

2. Probablemente se trate de Iavitz, uno de los miembros del Arbeiter Fraind (cf. infra). 
la mayoría de los detenidos profesaba ideas ácratas (Rivanera Carlés, 1986b: 25-28; 323-324). Para octubre de ese año los anarquistas molestaban lo suficiente como para merecer un artículo titulado "Los perversos" en el periódico El Sionista. ${ }^{3}$

El poaleisionismo o sionismo obrero tiene en Buenos Aires un origen doble. El primer grupo sionista socialista fue fundado en 1905 y al año siguiente publicó Dos Idishe Lebn ("La Vida Judía"), dirigido por Meir Polak (Regalsky, 1940: 95; Weinfeld, 1948: 458). Por otro lado, el 7 de agosto de 1906 se fundó la sección porteña de Poalei Tzion ("Obreros de Sion" en hebreo), organización sionista socialista inspirada en las ideas de Dov Ber Borojov. Su principal dirigente en Buenos Aires fue Zalman Sorkin, quien representaba una línea clasista, incluso considerada marxista ortodoxa, dentro del sionismo (Schers, 1992). En 1907 se integró a ella el núcleo dirigido por M. Polak. Esta organización aconsejaba votar por el Partido Socialista argentino (PS).

En octubre de 1905 se organizó el Grupo de Socialistas Rusos, primera expresión del socialismo judio en Buenos Aires, integrado por socialdemócratas y eseritas ${ }^{4}$ (Laubstein, 1997: 171). Este núcleo publicaba sus proclamas en ídish: para el $1^{\circ}$ de mayo emitieron una declaración llamando a los trabajadores judíos a plegarse a la manifestación del Partido Socialista. En efecto, aquel $1^{\circ}$ de mayo por primera vez participaron de una manifestación en Argentina (Lvovich, 2003: 96) obreros judíos "con sus lemas y pancartas escritos en ídish" (Avni, 1983: 285286). Aunque al poco tiempo se disolvió, el grupo alcanzó a fundar a principios de 1906 la Biblioteca Rusa, centro cultural obrero y socialista (Katz, 1980: 29), en la que se realizaban conferencias, veladas artísticas y debates abiertos entre las distintas tendencias políticas. Además de contar con la colección de libros en ruso e ídish más importante en la época, se dedicaba "a recoger contribuciones para las víctimas de los pogroms en Rusia, para los deportados a Siberia, para los diputados de la Duma que eran arrestados, para el movimiento revolucionario ruso en general y para los obreros huelguistas de la Argentina" (Mirelman, 1988: 72). La Biblioteca tenía carácter panruso y no sólo judío, aunque éste era el origen de la gran mayoria de sus participantes (Bilsky, 1987: 37), y en ella se hablaba ídish y ruso (Wald, 1955: cap. XXX).

El 20 de enero de 1907 Pinie Wald, Samuel Kaplansky y M. Brudnik fundaron la Organización Socialdemócrata Obrera Judía Avangard, ins-

3. Cf. Epelbaum de Weinstein (1987: 32). El sionismo político o nacionalismo judío es un movimiento fundado por el austrohúngaro Theodor Herzl, cuyo objetivo central fue promover la migración a Palestina y la creación allí de un Estado judío. Aquí sólo nos referiremos a su expresión en el movimiento obrero.

4. Miembros del Partido Social-Revolucionario ruso. 
pirada en el Bund de Europa Oriental, con sede en la Casa del Pueblo (México 2070).

El sindicalismo judío argentino nació el 28 de octubre de 1906 con la fundación del primer gremio de esta base étnica, el de los gorreros o sombrereros, ${ }^{5}$ seguido por el sindicato judio de actores (Bilsky, 1989: 35). En marzo de 1908 fue creado el Idisher Arbeiter Tzentr fir Profesionele Aguitatzion (llamado "Centro de Agitación Gremial entre los obreros israelitas"), integrado por socialdemócratas, sindicalistas y anarquistas (Mirelman, 1985: 15), con sede en la Casa del Pueblo. Su manifiesto fundacional, dirigido a gremios autónomos y adheridos a la FORA y a la UGT, proclamó entre sus objetivos:

Desarrollar la instrucción gremial de los obreros israelitas y propagar su participación activa en las sociedades gremiales. [...] En cada asamblea gremial donde asistan obreros israelitas concurrirán dos miembros del Centro Organizador para explicar en el idioma nacional el objeto de la asamblea para que los trabajadores citados tomen participación activa en las discusiones y resoluciones. ${ }^{6}$

Bajo su influencia (Katz, 1980: 29) fueron organizados el Sindicato de Obreros Panaderos Israelitas, formado inicialmente por judíos alemanes, ${ }^{7}$ y las secciones judias de los sindicatos de sastres y carpinteros. Las dos últimas respondian a la UGT o al Partido Socialista, mientras que el primero adhería a la FORA anarquista (Brusilovsky, 1940: 97). El Idisher Arbeiter Tzentr jugó un papel importante en el movimiento obrero judío pero se disolvió luego de 6 meses. También tuvieron corta vida las secciones gremiales: la de sastres funcionó sólo hasta 1909 y la de carpinteros fue disuelta por el sindicato.

\section{El anarquismo y la colectividad judia ashkenazi europeo-oriental}

La primera década del siglo XX constituye el periodo de hegemonía, en el movimiento obrero argentino, del anarquismo. Esta tendencia clasista (partidaria de la lucha de clases) tenía un fuerte componente ideológico individualista y moralista. Los anarquistas se organizaban en círculos, grupos o centros: organismos autónomos que tenían su propio nombre,

5. Dos Idishe Lebn (4 de diciembre de 1906), cit. en "Unión de Sombrereros", Cedinci, Fondo Edgardo J. Bilsky, caja n ${ }^{\circ} 35$.

6. La Protesta [LP], 14 de marzo de 1908, p. 1.

7. Cedinci, Fondo Edgardo J. Bilsky, caja n 35. 
hacian sus propias actividades, y hasta tenían su local y/o publicaban su propio periódico. Hacia 1904 sólo en la ciudad capital contaban con cerca de 4.000 militantes y por lo menos 51 centros (Suriano, 2001: 20, 50). La Protesta era el periódico de mayor difusión de la idea libertaria y cumplía la función de aglutinante y vocero excluyente de todo el movimiento. En él se manifestaban los conflictos internos y las luchas por el poder. Su papel dominante reflejaba la hegemonía alcanzada por la tendencia anarco-sindicalista, afin a las ideas de Piotr Kropotkin.

Durante la primera década del siglo XX el anarquismo tuvo un gran crecimiento internacional, en particular dentro de las poblaciones judias "atlánticas" de Nueva York, Londres, París y Buenos Aires, en todas las cuales se publicaban periódicos libertarios en ídish. La alta participación de judíos en este movimiento ha sido explicada, desde un punto de vista idealista, por las similitudes del elemento "trascendental" de la doctrina anarquista con el mesianismo, la ética o la escatología del judaísmo (Biagini, cit. en Moya, 2004: 39; Senkman, 2006: 104, 106, 110). Estos argumentos han sido refutados satisfactoriamente por Moya, con quien consideramos que la causa principal se encuentra sencillamente en que los judios provenían del Imperio ruso (2004: 39-40), donde el anarquismo había nacido y alcanzado su máxima intensidad entre las poblaciones judias del oeste y sudoeste (Avrich, 2005: 17). Esto no impide sugerir que el elemento individualista de la ideología libertaria podria haber tenido mayor audiencia entre los judíos, ya que en su psicología colectiva tenia fuertes raíces la aspiración a integrar la pequeña burguesía.

El trabajador judío, predispuesto a instalarse por su cuenta o a orientarse hacia el comercio, intentó escapar a esa condición de proletario. [...] Siendo un proletario reciente, o por lo menos no heredero de una tradición obrera, en su horizonte persistió la idea de escapar a la condición de trabajador manual asalariado. (Bilsky, 1989: 33)

En Buenos Aires la colectividad ashkenazí fue un terreno fértil para el desarrollo del anarquismo. En este caso tanta importancia como el origen de los inmigrantes tiene el hecho de que el movimiento libertario argentino estaba ya fuertemente extendido e incluso había alcanzado una posición de dirección. Es importante el hecho de que en 1904, cuando comienza a aumentar la inmigración obrera judía, estaba ya consolidada hacía tiempo la hegemonía, dentro del anarquismo argentino, de la tendencia llamada "organizadora" o anarco-sindicalista, afin a las ideas de Kropotkin, cuya influencia en Europa y particularmente en Rusia era notoria. En 1906, además, conquistó la dirección de La Protesta el grupo orientado por el español Eduardo García Gilimón, en el 
cual tenía un claro predominio la línea anarco-comunista de Kropotkin, quien fue desde entonces hasta fines de la década el teórico europeo más reproducido (Suriano, 2001: 101). Esta circunstancia no puede sino haber favorecido la integración de los judios kropotkinianos que formaban el círculo Arbeiter Fraind.

Otra condición que puede haber propiciado el acercamiento, ya que no necesariamente la adhesión, de los ashkenazim al anarquismo es su coincidencia en algunos oficios y gremios. Por ejemplo los panaderos, los sastres, los sombrereros y en general los empleos en las ramas del vestido y del mueble estuvieron entre los más ejercidos por trabajadores judios (Bilsky, 1989: 31), y al mismo tiempo eran gremios enrolados en la FORA dirigida por el anarquismo (como panaderos y sombrereros) o donde éste tenía influencia (Bilsky, 1985: 84; Suriano, 2000: 311).

\section{Los circulos anarquistas judios}

Los agrupamientos anarquistas judíos compartían el carácter de clase del conjunto del movimiento libertario argentino: eran agrupaciones obreras dirigidas por obreros; "ninguno de los dirigentes de los partidos y grupos anarquistas judíos, ni los que escribian sus órganos, tenian formación universitaria. Todos eran obreros" (Brusilovsky, cit. en Bilsky, 1987: 84). Dentro del anarquismo judío había distintas variantes ideológicas: anarco-comunistas, anarco-individualistas e incluso anarcosionistas, a los cuales se agregaron, probablemente hacia la segunda década del siglo, los anarco-idishistas (Katz, 1946: 161-162). Pero los anarco-sionistas en la Argentina de esta década, más que miembros de una vertiente libertaria específica, parecen haber sido anarquistas influidos por, o en tránsito hacia, el poaleisionismo. En efecto, Biagini constató la simpatía de muchos anarquistas por Poalei Tzion (cit. en Moya, 2004: 29). Para el caso porteño, ya Mirelman había registrado que "bajo la influencia inicial de Poale Sión, no pocos anarquistas de Buenos Aires llegaron a simpatizar con el sionismo obrero" (1988: 231), cuando Rawin y López (2001: 182-184) señalaron la impronta poaleisionista presente en la Asociación Racionalista Judía, organización libertaria fundada en 1916 como fusión de diversos núcleos preexistentes. Aquí probaremos la fuerte influencia del Poalei Tzion en el círculo Protest.

En la época se identificaba a los judíos por su "nacionalidad", con lo cual los círculos de ashkenazim europeo-orientales eran llamados y se llamaban a sí mismos "rusos" porque provenían del Imperio zarista. Podemos identificar seis grupos judios anarquistas entre 1905 y 1909. Así como el Grupo de Obreros Rusos en 1905, el círculo Amor al Trabajo ha sido rastreado únicamente en 1906 (Suriano, 2001: 55). En octubre de 1907 el grupo Juventud Rusa comienza a desarrollar sus actividades 
en un local en Cuyo $2594,{ }^{8}$ pero sólo hasta noviembre hallamos referencias, las cuales evidencian un estrecho vínculo con el Arbeiter Fraind. ${ }^{9}$

El último en aparecer fue el núcleo Burevéstnik. Nacido a fines de mayo de $1908,{ }^{10}$ su actuación ha sido registrada hasta 1909; su único miembro conocido fue Simón Radowitzky. ${ }^{11}$ El motivo de su creación fue difundir la idea libertaria en idioma ruso, entre los obreros rusohablantes, complementando a los círculos ya existentes que hacian lo propio en ídish. ${ }^{12}$ En este sentido es correcto afirmar que los anarquistas judios "se acercaron a la organización anarquista general como grupo lingüístico" (Schers, 1992). Burevéstnik ("El Petrel”, es decir: el que anuncia la tempestad) era el nombre de un periódico anarco-comunista de tendencia organizadora, que vio la luz en París entre 1906 y 1910, bajo la dirección de exiliados rusos (Rivanera Carlés, 1986a: 56). En Buenos Aires este círculo se reunía en Lavalle 2196 (Moya, 2004: 31), el local de la Idishe Populere Bibliothek, que Radowitzky frecuentaba, ${ }^{13}$ y del Arbeiter Fraind.

Párrafo aparte merece la Schvartzer Bande ("Banda Negra"), señalada por Rivanera Carlés (1986b: 296-299) -cuyas únicas fuentes son las producidas por la policía que dirigía Falcón- como sección porteña de la agrupación anarquista terrorista rusa Chernoe Znamia ("Bandera Negra"). Según el operativo policial reflejado en Caras y Caretas (18 de enero de 1908), Abraham Hartenstein, un calderero judío de 19 años que había sido arrestado, era el fundador del grupo (Moya, 2004: 2930). La policia habria encontrado armas y bombas cuyo destino era el de volar edificios públicos. Ya el propio Rivanera Carlés se vio obligado a confesar que el tal Hartenstein "en los círculos ácratas era sindicado como un confidente de la policía" (1986b: 299). En realidad se trataba de una patota de matones que actuaban al servicio de la burguesía judía contra los obreros de su misma "nación". El empresario judío Peiche Vartman los envió a golpear a los empleados organizados de su sastrería, por lo que éstos se declararon en huelga; el Idisher Arbeiter Tzentr y el sindicato de sastres lanzaron conjuntamente un boicot contra este taller por albergar a los "hooligans" de la Schvartzer Bande, a quienes denunciaron como autores de un "pogrom" contra los trabajadores. ${ }^{14}$

8. Cf. $L P, 17$ de octubre de 1907.

9. Cf. $L P, 30$ de octubre de 1907, 12 de noviembre de 1907 y 15 de noviembre de 1907.

10. Cf. Idishe Abtheilung [IA], en LP, 29 de mayo de 1908 y 30 de mayo de 1908.

11. Cf. La Vanguardia 14 de enero de 1910.

12. Cf. $I A$, en $L P, 29$ de mayo de 1908 y 30 de mayo de 1908.

13. Cf. La Vanguardia 14 de enero de 1910.

14. Cf. $I A$, en $L P, 4$ de abril de 1908 y 14 de abril de 1908. 
Por lo demás, era frecuente que los delincuentes comunes se disfrazaran con ropaje libertario, y algunas evidencias sugieren que éste era el caso de los tratantes de blancas judíos (Moya, 2004: 22-24). Es decir que los explotadores judios, de sastres o de prostitutas, encubrian sus actividades ilegales con el lenguaje del anarquismo.

No queremos dejar sin mencionar la existencia de otra organización "rusa" vinculada al anarquismo: la Sociedad Rusa de Desarrollo Intelectual y Socorros Mutuos, integrada por libertarios y marxistas (Rivanera Carlés, 1986b: 31), cuyos mítines contra los pogroms en Rusia eran anunciados en La Protesta. ${ }^{15}$

Repasaremos aquí las trayectorias de los círculos Arbeiter Fraind y Protest.

\section{Arbeiter Fraind (1905-1918)}

Fue "la primera organización anarquista judía en el país" (Dujovne 2008: 125), y entre las de la primera década la más duradera e importante (Rivanera Carlés 1986b: 32), la que "agrupó a su alrededor a casi todos los anarquistas y tuvo una participación muy importante en la organización gremial de los trabajadores judios y en la vida cultural del trabajo en la calle judia" (Katz, 1946: 164). Fue fundada en 1905 por militantes del grupo londinense Arbayter Fraynd ${ }^{16}$ que llegaron entonces a la Argentina. Su actividad se registra desde el mítin que la policía consignó en diciembre de ese año (Moya 2004: 28).

Su primer dirigente fue Boris London (o Celman o Gelman) (Moya, 2004: 29), carpintero que en 1909 contaba con 32 años. Pertenecian al grupo los hermanos Moishe y Abraham Shutz, de 21 y 24 años respectivamente, sastres de profesión que vivian en Lavalle 2637, barrio de Once; Samuel Samburski, jornalero de 21 años domiciliado en Tucumán 1958, y el sastre Iavitz ${ }^{17}$ (Katz, 1980: 33), ${ }^{18}$ de quien Katz (1946: 162163) recuerda tanto su origen londinense como sus encendidos alaridos

15. Cf. "Matanza de hebreos", en $L P, 12$ de octubre de 1907 y 26 de noviembre de 1907. 16. Se trata de la organización, hegemónica en la Federación de Anarquistas Judíos de Gran Bretaña, que dirigia Rudolf Rocker y era conocida en inglés como Worker's Friend.

17. Probablemente se trate de José Yavich, detenido en la redada de marzo de 1906 (cf. supra).

18. Los datos han sido tomados de informes policiales o diplomáticos de 1909 relevados por Rivanera Carlés (1986b: 70; 74; 320). Las edades deben ser tomadas como aproximadas. Los hermanos Shutz y Samburski fueron consignados (¿erróneamente?) como miembros del grupo Burevéstnik. 
en los restaurantes judíos donde los trabajadores discutían de política. También parece haber sido miembro un tal Nuger. ${ }^{19}$

El círculo, de orientación anarco-comunista, ${ }^{20}$ recibió un impulso con la llegada desde Londres, a fines de 1907, de A. (Alef) Shapiro. De oficio bastonero, ${ }^{21}$ se dedicaba además al teatro y llegó a Buenos Aires junto con su esposa, la actriz Berta Kornfeld, y los actores Dovid Reyts, Moris Akselrod y los Maryenhof (Katz, 1946: 163; Prager, 1990: 380). ${ }^{22}$ Según Katz, su presencia generó revuelo entre los anarquistas: de bigotes oscuros y modales refinados, "con su hablar tan pausado y con su discurso tan ordenado, con sus términos tan propios de él, (...) también comenzó a inmiscuirse en las discusiones con los socialistas, donde lograba imponerse con su tranquilidad y con la ayuda de sus modos tan especiales de hablar". El grupo se nucleó en torno suyo y fue él quien dirigió el periódico (1946: 163). Sin embargo, ya para agosto de 1908 pasó a dedicarse enteramente al teatro, poniendo en escena junto a su esposa obras de Octave Mirbeau (Katz, 1946: 167).

Moishe Shutz fue señalado en 1909 como secretario del grupo. En Rusia habría pertenecido, junto con Simón Radowitzky, a un grupo ácrata dirigido por Petroff (Rivanera Carlés, 1986b: 74). Fue deportado tras el atentado contra Falcón; vivió en París, lo detuvieron cuando cruzaba la frontera con España, pasó por Londres y finalmente recaló en los Estados Unidos (Rocker, 1949: 276-278), donde fue uno de los principales redactores del Fraie Arbeter Shtime (Schiller, 2006: 41) de Nueva York, al cual siguió vinculado al menos hasta 1945 (Rocker, 1952: 424).

Hacia mediados de 1907 la secretaria del Arbeiter Fraind funcionaba en la Casa del Pueblo, sede del movimiento obrero ubicada en México 2070. Pero cuando los miembros del Partido Socialista que administraban el lugar les aumentaron el alquiler debieron cambiar de local. ${ }^{23}$ Probablemente hayan pasado a tener su base en el local de la Juventud Rusa, en Cuyo 2594. ${ }^{24}$ En 1908 alquilaron un local en Lavalle 2196 (barrio de Once), donde instalaron la Idishe Populere Bibliothek, que fue también sede del grupo Burevéstnik y cuyos libros consultaba asiduamente Simón Radowitzky. ${ }^{25}$ La biblioteca abría de 8 a 10 de la noche, y

19. Cf. $L P, 17$ de junio de 1908. Probablemente se trate de Otto Nuger; cf. $L P, 20$ de junio de 1908, 21 de junio de 1908 y 24 de junio de 1908.

20. Cf. Juventud, año VI, n 49 (julio de 1916), p. 55.

21. El shtekelemajer (bastonero) elaboraba palos de madera para usar como bastones o paraguas, siendo así una variante del carpintero.

22. Según Prager, el grupo salió de Londres hacia Buenos Aires en 1906.

23. Federico Aestriz, “¡Por anarquistas!”, en $L P, 13$ de agosto de 1907, p. 2.

24. Cf. $L P, 30$ de octubre de 1907 y 15 de noviembre de 1907.

25. Cf. La Vanguardia, 14 de enero de 1910. 
en ella organizaron una "escuela nocturna", ${ }^{26}$ actividad típica entre los obreros judíos que buscaban aprender castellano.

En cuanto a la actividad que llevaban a cabo, en un principio ocupó un lugar central la difusión de la prensa y la literatura anarquista en ídish llegada del extranjero. El círculo difundía los periódicos Der Arbayter Fraynd de Londres, cuya distribución en Argentina era muy exitosa (Wald, 1955: cap. XXX), y el Fraie Arbeter Schtime de Nueva York (Katz, 1980: 29), los cuales se podian hallar en los alrededores de Plaza Lavalle, siendo así los primeros periódicos de izquierda en ídish que circularon en Buenos Aires (Schers, 1992). También distribuía la revista Germinal, editada por el Arbayter Fraynd inglés, logrando que sea muy conocida entre la juventud (Katz, 1946: 164). ${ }^{27}$ Además era requerido para proveer oradores en asambleas gremiales ${ }^{28}$ lo cual muestra la preocupación del conjunto del anarquismo (no sólo de los judios) por llegar a los obreros de habla ídish. Según Wald (1955: cap. XXX) otra actividad frecuente del Arbeiter Fraind consistia en asistir a eventos organizados por otras agrupaciones judias y provocar su disolución. Tenía un importante poder de convocatoria: en la conferencia que organizaron el 12 de enero de 1908 en la Plaza Lavalle lograron reunir, según la policía, 250 personas (Rivanera Carlés, 1986b: 32).

En 1907 se orientaron hacia la edición de su propio órgano de prensa, Dos Arbeter Lebn ("La Vida Obrera"), en ídish y bajo la dirección de Shapiro, quien habría sido su principal redactor (Katz, 1946: 164; idem, 1980: 30) junto a los hermanos Shutz (Bilsky, 1987: 35). Alcanzaron a ver la luz 8 números, los cuales "tuvieron una gran influencia, junto con el redactor, sobre el movimiento anarquista judio en la Argentina" (Katz, 1946: 164). Las fuentes no permiten precisar su periodicidad ni el espacio temporal durante el cual vio la luz. Ha sido fechado a principios de 1908 y como semanario (Katz, 1946: 163; Wald, 1955: cap. XXX). En julio de 1907 fue anunciado como un periódico mensual en la primera plana de La Protesta. Algunas evidencias ${ }^{29}$ sugieren que, aunque tenía dificultades para salir, los primeros números pueden haber visto la luz durante la segunda mitad de 1907. El carácter pionero de Dos Arbeter Lebn (fue el primer periódico anarquista en ídish en toda Sudamérica) reflejaba el carácter temprano de la inmigración judia argentina.

De la trayectoria posterior del Arbeiter Fraind hay algunos datos. Participó activamente de los enfrentamientos del Centenario, teniendo

26. Cf. $L P, 2$ de septiembre de 1908, p. 2.

27. Rocker (1949: 149) confirma que Germinal tenía lectores en Buenos Aires.

28. Cf. $L P, 5$ de octubre de 1907, p. 2.

29. Cf. $L P, 24$ de julio de 1907, 29 de septiembre de 1907, 30 de octubre de 1907 y 24 de noviembre de 1907. 
un orador en el acto que coronó la manifestación del 8 de mayo de 1910 (Rivanera Carlés, 1986b: 80-82). Probablemente fue este círculo el que organizó en 1911 los festejos por el 25 $5^{\circ}$ aniversario del Arbayter Fraynd de Londres, que tuvieron su edición en Buenos Aires (Rocker, 1949: 304). En 1915 fundó la Idishe Fraie Bibliothek, junto con el grupo Buscadores de la Verdad. Al año siguiente se separaron: estos últimos (de inspiración tolstoiana) se fusionaron con el sector "idishista" de la Liga Racionalista (Bilsky, 1987: 85-86), fundando la Idishe Ratsionalistishe Ligue, de orientación anarquista, que tendría seis décadas de existencia (Schiller, 2006: 42). El Arbeiter Fraind se disolvió en 1918 (Bilsky, 1987: 85).

\section{Protest ("Grupo ruso La Protesta") (1908)}

La existencia del grupo Protest ha permanecido casi completamente oculta en la historiografia. Nació dos semanas después del inicio de la Idishe Abtheilung (sección en ídish en La Protesta), formado por quienes se encargaban de ella y con el objetivo de garantizar su existencia diaria. ${ }^{30}$ No sólo fue el iniciador ${ }^{31}$ y responsable de esa sección (hasta hoy atribuida a los "anarquistas judíos" en términos generales), sino también de la revista Lebn un Fraiheit, ${ }^{32}$ que hasta ahora había sido atribuida al Arbeiter Fraind (Epelbaum de Weinstein, 1987: 14; Bilsky, 1989: 35; Senkman, 2006: 107; Dujovne, 2008: 126). La tendencia de este círculo era anarco-individualista, ${ }^{33}$ lo que lo oponía al Arbeiter Fraind de orientación anarco-comunista, y mantenía una estrecha relación con el grupo Poalei Tzion. Las principales figuras de este círculo fueron P. Sprinberg e I. Edelstein, quienes dirigieron Lebn un Fraiheit (Rollansky, 1940: 81; Katz, 1946: 167).

Yitzjok Edelshtein (Itzjok Edelstein) nació en 1890. Había participado del Poalei Tzion cuando llegó a Buenos Aires, donde a los 17 años ya militaba en el anarquismo. Las fuentes lo muestran en el local de Cuyo 2594 y colaborando con la recaudación de fondos para Dos Arbeter

30. Cf. $I A$, en $L P, 5$ de abril de 1908, 7 de abril de 1908 y 8 de abril de 1908 .

31. Cf. $I A$, en $L P, 5$ de junio de 1908.

32. Cf. $L P, 26$ de junio de 1908.

33. Cf. Juventud, año VI, $n^{\circ} 49$ (julio de 1916), p. 55, y Katz (1946: 167). El círculo no nació identificándose con esta orientación sino que probablemente se haya ido deslizando hacia ella, ya que un mes después de haberse formado se declaraba como "grupo anarco-comunista"; cf. $I A$, en $L P, 9$ de mayo de 1908. El individualismo debió estar más definido 3 meses después, cuando Edelstein tradujo "Así hablaba Zarathustra" para Lebn un Fraiheit. 
Lebn, ${ }^{34}$ por lo que pudo haber pertenecido tanto a Juventud Rusa como al Arbeiter Fraind. Tenía 18 años cuando fue el linotipista y principal redactor de la Idishe Abtheilung. Para Lebn un Fraiheit tradujo, del castellano al ídish, partes del Así hablaba Zarathustra de Nietzsche. Estudió hasta llegar a farmacéutico (Katz, 1946: 167-171).

Pinhas-David Yakovlevich Shprinberg (1889-1974), o Pedro Sprinberg, nació en Zguritsa, Besarabia, y en 1903 viajó a la Argentina. Su padre había llegado antes a Rosario, donde se convirtió en un rico hombre de negocios (Katz, 1946: 167-170). Tenía 18 y 19 años cuando militó en el anarquismo, en el cual participó al menos desde noviembre de $1907 .{ }^{35}$ En 1910 se casó con Catalina Stoliar, hermana de Motya Stoliar (1886-1951), figura de primer orden del sionismo socialista, quien fue gerente del primer cotidiano en ídish de Buenos Aires, Dos Idishe Lebn (Weinfeld, 1948: 458) y en 1914 fundó Di Idishe Tzaitung ("El Diario Israelita"), el diario más importante de la colectividad judía porteña (Rollansky, 1940: 81). Luego de 1910 Sprinberg abandonó el anarquismo y se convirtió en teósofo. Entre 1913 y 1914 codirigió con P. Katz la revista Shtrahlen ("Rayos") (Katz, 1946: 189). Su actividad periodística continuó como corresponsal de Di Idishe Tzaitung en Paraguay, en Rosario y finalmente en Montevideo, donde se radicó en 1933. Allí fue director del diario en ídish Uruguaier Tog ("El Día Uruguayo"), que salió hasta 1935. Al fin de una trayectoria que lo alejó del anarquismo y lo acercó al sionismo, en 1937 fue secretario de la sección uruguaya de la Agencia Judía para Eretz Israel (Moskovicz, 2011).

No es el único lazo de este grupo con el sionismo socialista: las dos publicaciones periódicas que encaró representaron una colaboración con los escritores Pinie Katz y Noaj Vital (Epelbaum de Weinstein, 1987: 14; 16). El primero es quizá la figura más importante de la cultura ídish y de la izquierda judía en Argentina. Su pluma aparece por primera vez en la sección judía de La Protesta, mientras era secretario del Poalei Tzion (Schers, 1992). En 1917 colaboró con la fundación del Poalei Tzion en el Uruguay (Moskovicz, 2011). Tras la revolución rusa fundó y dirigió el diario de izquierda en ídish Di Presse, cotidiano que simpatizaba con la URSS (Camarero, 2007: 300). En la década de 1930 se convirtió en uno de los principales dirigentes del antifascismo y fue el primer presidente del Idisher Cultur Farband (ICUF), organización impulsada por el PC. Noaj (Noé) Vital fue un escritor que abordó la descripción de la vida proletaria judia porteña. Perteneció al sionismo socialista (Katz, 1946: 160) y participó, quizá con sus primeros textos, del diario de esta tendencia Dos Idishe Lebn (Mirelman, 1985: 10).

34. Cf. $L P, 30$ de octubre de 1907 y 15 de noviembre de 1907.

35. Cf. $L P, 30$ de noviembre de 1907. 
Lebn un Fraiheit ("Vida y Libertad") tenía una decidida apertura ideológica: "La mayoria de sus colaboradores no compartian las ideologías de Kropotkin, Tolstoi, Bakunin y otros" (Weinfeld, 1948: 458). Fue anunciada como revista mensual ilustrada de ciencias, artes y literatura, ${ }^{36}$ es decir que tenía una clara orientación cultural, aunque sólo alcanzó tres números. Su contenido principal eran artículos, muchos extraídos de La Protesta y traducidos al ídish, noticias y chistes (la mayoria, anticlericales) (Katz, 1946: 167-170).

\section{La colaboración de los círculos y la Idishe Abtheilung (15 de marzo al 7 de junio de 1908)}

La Idishe Abtheilung fue -o convirtió a La Protesta en- el segundo diario en ídish de la Argentina y el más duradero hasta entonces, ya que el primero -Dos Idishe Lebn- se había publicado no más de 20 días en 1906. Fue además el único caso en la historia argentina de un diario no judío con una sección en ídish, y el primer periódico que incluyó contenido en ambos idiomas. La página fue publicada en forma diaria desde el 15 de marzo hasta el 7 de junio de 1908, alcanzando un total de 72 números.

La sección existió en la medida en que expresó la colaboración entre los grupos Arbeiter Fraind y Protest. Para su lanzamiento, el primero organizó una velada a beneficio de la Idishe Abtheilung, ${ }^{37}$ en la que a su vez fueron publicitados sus mítines y conferencias. El 19 de abril el grupo Protest fue invitado a participar de un mitin del Arbeiter Fraind en el local de Lavalle, en el que éste resolvió, además de convocar al acto anarquista del $1^{\circ}$ de mayo en Plaza Lorea, propagandizar la Idishe Abtheilung y comprometerse con los emprendimientos organizados por Protest para el diario; los presentes decidieron también efectuar una reunión de ambos círculos. ${ }^{38}$ Probablemente haya sido en ella donde se decidió una politica en común para contar, en el próximo Día Internacional del Trabajador, con una columna judía. En efecto, los dos grupos invitaron a todos los trabajadores judíos a reunirse en el local de Ayacucho 1059, para marchar desde alli bajo una misma bandera hasta la Plaza San Martín, donde finalizaba la movilización. ${ }^{39}$ La convocatoria diferenciada

36. Cf. $I A$, en $L P, 6$ de junio de 1908 y $L P, 26$ de junio de 1908.

37. Cf. $L P, 14$ de marzo de 1908 , p. 2, y 15 de marzo de 1908 , p. 2, e $I A$, en $L P, 15$ de marzo de 1908 y 24 de marzo de 1908.

38. Cf. $I A$, en $L P, 22$ de abril de 1908.

39. Cf. $I A$, en $L P, 1$ de mayo de 1908. 
habría logrado atraer a unos 300 judíos. ${ }^{40}$ Fue así que hubo en los actos anarquistas oradores que dieron discursos en ídish (Moya, 2004: 31).

Esta relación de camaradería no se circunscribía a la redacción de la sección judía. Ambos círculos formaron parte del "Comité pro Libertad de Imprenta", en el cual once centros ácratas se organizaron contra el proyecto de ley para limitar la circulación de la prensa obrera, impulsado por el jefe de policía Ramón Falcón (Suriano, 2001: 184), pero además crearon el "Sub-Comité Judío Popular por la Libertad de Prensa", en el cual integraron al Idisher Arbeiter Tzentry al grupo Burevéstnik. ${ }^{41}$ Por su militancia, varios de los miembros de ambos círculos fueron detenidos por la policia. Abraham Shutz y Pedro Sprinberg fueron arrestados a mediados de mayo; $;^{42}$ Itzjak Edelstein lo había sido un mes antes. ${ }^{43}$ Pero no sólo las actividades de los dos círculos anarquistas eran anunciadas en la sección, sino también las del grupo Poalei Tzion, cuyo local quedaba en Lavalle $2147,{ }^{44}$ es decir en frente del que tenía el Arbeiter Fraind.

Acerca del porqué de la desaparición de la Idishe Abtheilung, hasta ahora sólo contábamos con el dato de Lewin de que "para más tiempo no alcanzaron los recursos financieros" (1983: 165). En efecto, parece ser que Edelstein debió cubrir parte de los gastos con sus propios ingresos (Katz, 1946: 171). Pero hay una explicación más profunda. El 5 de junio una nota anticipó que la sección judía saldría sólo dos días más. El empeoramiento de las condiciones económicas es mencionado como uno de los motivos, pero no el único. Se denuncia como otra de sus causas la frialdad y hostilidad de "supuestos camaradas" hacia el grupo Protest y la Idishe Abtheilung. Al dia siguiente directamente adjudicaron la responsabilidad de la muerte de la sección judia al grupo Arbeiter Fraind y a la colaboración directa o indirecta del Idisher Arbeiter Tzentr. ${ }^{45}$ Evidentemente el grupo Protest fue enfrentado por el resto de los anarquistas judios que militaban entre los trabajadores de la colectividad, los cuales consiguieron el apoyo de la dirección de $L a$ Protesta para quitarlos del diario. Podemos suponer dos motivos para esta ruptura entre los círculos. Por un lado, es posible que la orientación anarco-individualista de Protest haya chocado con la tendencia anarcocomunista del Arbeiter Fraind. Ya en la columna "Sobre el trabajador judío" de la Idishe Abtheilung se había ventilado un debate político entre

40. Cf. $I A$, en $L P, 3$ de mayo de 1908.

41. Cf. $I A$, en $L P, 29$ de mayo de 1908.

42. Cf. $I A$, en $L P, 16$ de mayo de 1908.

43. Cf. $I A$, en $L P, 16$ de abril de 1908 y 17 de abril de 1908 .

44. Cf. $I A$, en $L P, 22$ de marzo de 1908, 31 de marzo de 1908, 5 de abril de 1908 y 17 de abril de 1908 .

45. Cf. $I A$, en $L P, 5$ de junio de 1908 y 6 de junio de 1908. 
Itzjak Edelstein y Moishe Shutz, en el cual se expresaban posiciones divergentes que se habian manifestado previamente en una reunión del Idisher Arbeiter Tzentr. ${ }^{46}$ Se explicaria así que haya sido el Arbeiter Fraind el que haya conquistado el favor del grupo editor de La Protesta, afin a la linea kropotkiniana. Otra causa de discordia puede haber sido la cercanía de Protest con el Poalei Tzion, y sobre todo el espacio que éste obtenía en la Idishe Abtheilung, si tenemos en cuenta que no sólo las actividades del grupo sionista socialista eran difundidas en la página, sino que muchos artículos eran redactados por sus miembros. Uno de ellos, Katz, recuerda que quienes escribieron para la sección judia "no sentían sobre sí ningún tipo de control, a pesar de que eran en general opositores al anarquismo" (1946: 171).

Poco después, sin embargo, los dos grupos participaron del comité Iugnt ("Juventud"), impulsado por el grupo Poalei Tzion para luchar contra los proxenetas judios, que actuó desde octubre de 1908. En él participaron entre otros los miembros del Arbeiter Fraind (Katz, 1946: 164-165) y "algunos anarquistas-individualistas" (Wald, 1955: cap. XXX), que probablemente fueron los miembros de Protest, quienes reflejaron el episodio en Lebn un Fraiheit. ${ }^{47}$ Se trata del último registro del grupo Protest.

\section{Conclusión}

La presencia judía en el anarquismo de Buenos Aires en aquella década ha sido estudiada por Moya. Su conclusión es que la participación judía dentro del movimiento libertario porteño fue, desde 1905 hasta 1910, desproporcionalmente elevada: entre los anarquistas era judio un porcentaje mucho mayor que el $2 \%$ que representaban sobre el total de la población de la ciudad, alcanzando un pico entre 1909 y 1910, cuando el 22\% de los deportados ácratas fueron judíos (2004: 32, 37). Podemos reforzar esta tesis si comparamos la cantidad de círculos judíos con el total de grupos anarquistas de la ciudad de Buenos Aires. $\mathrm{El}$ resultado es que los primeros representaron durante todo el lustro un porcentaje mucho más elevado que aquel $2 \%$.

46. Cf. $I A$, en $L P, 1$ de abril de 1908, 7 de abril de 1908 y 8 de mayo de 1908. En su artículo, M. Shutz reivindica los aportes de Johann Most y P. Kropotkin, exponentes del anarco-comunismo.

47. Cf. Mirelman (1988: 289; 360-361) y M. Polak, "La juventud israelita", en LP, 20 de octubre de 1908. 


\begin{tabular}{|l|c|c|c|}
\hline Año & Número total de círculos* & Círculos judíos & Porcentaje \\
\hline 1905 & 25 & 2 & $8,0 \%$ \\
\hline 1906 & 37 & 2 & $5,4 \%$ \\
\hline 1907 & 40 & 2 & $5,0 \%$ \\
\hline 1908 & 38 & 3 & $7,9 \%$ \\
\hline 1909 & 37 & 2 & $5,4 \%$ \\
\hline
\end{tabular}

*Los datos de esta columna han sido tomados de Suriano (2001: 50).

Distinta es la cuestión de cómo ponderar la presencia anarquista sobre el conjunto de judíos de Buenos Aires. Refiriéndose a éstos durante el segundo lustro del siglo XX, Rivanera Carlés afirma, seguramente exagerando, que "la mayoría era anarquista" (1986b: 31). Pero sí parece haberlo sido una primera minoria, ya que también otras fuentes sostienen que al menos hasta el año 1908 los anarquistas fueron el grupo más fuerte en el ambiente de obreros judíos de Buenos Aires (Schers, 1992), y que se hacian escuchar más que otras tendencias (Wald, 1955: cap. XXX). Si tomamos la existencia de periódicos, sostenida en el tiempo, como expresiones de una actividad militante, podemos afirmar que entre los inviernos de 1907 y 1908 el anarquismo llevó amplia ventaja sobre cualquier otra corriente, ya que prácticamente fue la única organización de izquierda que tenía publicaciones en ídish. Pero este elemento nos parece ser, a la vez que expresión o consecuencia, una de las causas de esta temprana y breve hegemonia libertaria sobre la clase obrera judía.

Nuestra hipótesis es que un factor decisivo que explica la capacidad del anarquismo para alcanzar con su prédica y organización a los judíos porteños fue su posición politica de rechazo a la nacionalización de los extranjeros como medio de participación política, lo cual no es más que aplicar la tesis de Falcón (1986-1987) al caso que nos toca. Esta postura llevó a los anarquistas a aceptar el idioma de los inmigrantes como instrumento de comunicación al interior de la clase obrera y a organizar conferencias y editar periódicos en las diferentes lenguas para intentar alcanzar con la propaganda a la totalidad de los trabajadores, lo que entre los judíos valía tanto para el ídish como para el ruso. En efecto, los anarquistas "accedian a una propaganda oral e impresa en ídish dentro de los sindicatos y con fondos sindicales" (Lewin, 1971: 161): ya vimos que requerian oradores en ídish para las asambleas gremiales. Sólo esto explica que los grupos anarquistas judíos, además de ser integrados en el movimiento, tuvieron la potestad para publicar una página en ídish (de un total de cuatro) en el órgano ácrata de mayor difusión, lo cual constituía "un esfuerzo para apelar a los inmigrantes 
judíos que todavía no dominaban el castellano" (Kirstein, 2009: 16). Con la Idishe Abtheilung, La Protesta "se empezó a vender fuertemente en la calle judía. Era comprada con interés en apoyar la página dedicada a la vida cultural judia" (Katz, 1946: 171). Pinie Wald reconocia que la sección de La Protesta "constituía una prueba del interés positivo y de la actitud de los anarquistas no judios hacia el ídish (como a todos los otros idiomas)" (1955: cap. XXX). Mirelman concluye que "este hecho refleja claramente el positivo interés del movimiento anarquista en los grupos lingüísticos y la ligazón ideológica entre ellos, fuesen o no judíos" (1988: 230). De alguna forma, la posición ácrata respecto del idioma fue la que luego adoptaron los leninistas, es decir los iskrovzes del PS (cf. infra) y años después el Partido Comunista argentino en su primera etapa. En sintesis, el anarquismo

resultó más consecuente en su universalismo, al predicar el cosmopolitismo y respetar las peculiaridades de cada grupo étnico, a diferencia del socialismo que trataba de imponer a los extranjeros la necesidad de la naturalización y discriminaba entre sus afiliados según tuviesen o no carta de ciudadanía. (Bilsky, s/f: 22)

En efecto, los socialdemócratas judíos tenían una relación más conflictiva con el PS, el cual incentivaba la asimilación, la nacionalización y la adopción de la lengua castellana como medios para participar de la política local. El ejemplo paradigmático de esta actitud es el de los hermanos Dickmann, dirigentes nacionales del Partido, quienes evitaron dar discursos en ídish y militar en el seno de la colectividad. ${ }^{48}$ Además la organización judía socialdemócrata Avangard, que buscaba compensar esta carencia, se dividió entre iskrovzes y bundistas. Los primeros ("chispistas", por el periódico Iskra que publicaba Lenin en Rusia) eran partidarios de integrarse al PS, en cuyo seno formaron el Centro Avangard, grupo de propaganda idiomática subordinado al Comité Central, con el objetivo de llevar adelante la política del partido dentro de la colectividad; los segundos defendían el uso exclusivo del ídish y la existencia de una organización socialista judía autónoma. La dirección del PS debió intervenir en la disputa en mayo de 1908, y aunque favoreció a los iskrovzes, ${ }^{49}$ se logró llegar a una fórmula de compromiso. Esta crisis seguramente es lo que explica la ausencia de un periódico en ídish desde la fundación del Avangard en enero de 1907,

48. Para un análisis pormenorizado de la política del PS hacia los judíos, cf. Mirelman (1988), pp. 93-101.

49. Cf. $I A$, en $L P, 24$ de mayo de 1908. 
hasta agosto de 1908. Para esa fecha, por el contrario, los anarquistas ya tenian grupos que actuaban en ídish (Arbeiter Fraind y Protest) y en ruso (Burevéstnik) y habían editado 8 números de un periódico y una sección en ídish en La Protesta.

El invierno de 1908 marca el punto en que la actividad de los anarquistas al interior de la colectividad judía comienza a apagarse para no volver a recuperar nunca todo su esplendor. Hay varios elementos que evidencian esto y podrian explicarlo. Por un lado, con el retiro de Shapiro dejó de salir Dos Arbeter Lebn, que como vimos tenía una influencia importante. Al mismo tiempo La Protesta dejó de tener sección ídish, lo que seguramente la privó de parte de su público judio previo. El círculo Protest la reemplazó con una revista que no tuvo más que tres números, tras los cuales probablemente sus miembros hayan abandonado el movimiento anarquista. Y luego de 1908 no hubo ningún periódico anarquista en ídish hasta $1917 .^{50}$

Si los anarquistas dejaron por su propia cuenta un lugar vacante, las demás corrientes políticas buscaron ocuparlo. En primer lugar los socialistas: en agosto de 1908 apareció el periódico mensual Der Avangard ("La Vanguardia"), editado por la organización bundista Avangard, bajo la dirección de Sh. Kaplansky y P. Wald. Evidentemente la disputa con los libertarios era considerada una tarea central, porque en todos sus números publicaron un artículo sobre el anarquismo (Kirstein, 2009: 16). También los iskrovzes del PS se lanzaron a conquistar al público de habla ídish: Di Shtime fun Avangard ("La Voz de la Vanguardia"), órgano mensual del Centro Avangard del PS, comenzó a publicarse en 1909 (Laubstein, 1997: 175). El periódico sionista Di Idishe Hofnung ("La Esperanza Judía") comenzó a publicarse el 15 de agosto de 1908. Poalei Tzion cobró breve impulso con la llegada en 1909 de León Jazanovich, quien emprendió la publicación de Broit un Ehre ("Pan y Honra"), pero fue deportado durante los enfrentamientos del Centenario junto con Zalman Sorkin.

En el caso del anarquismo judío porteño, parece claro que las diferentes tendencias aparecen vinculadas a distintos origenes sociales. Los oficios de todos sus miembros no dejan dudas acerca de la composición netamente obrera del grupo anarco-comunista Arbeiter Fraind. Por el contrario, del círculo anarco-individualista Protest sabemos que Sprinberg era hijo de un rico hombre de negocios y que Edelstein pudo estudiar hasta llegar a farmacéutico, lo que nos habla de mayores posibilidades económicas. ¿Hasta qué punto el carácter de clase explica la orientación ideológica de cada grupo? ¿Es lícito suponer que los sas-

50. Ese año apareció Der Fraie Arbeter ("El Obrero Libre"), editada por los círculos anarquistas racionalistas judíos (Dujovne 2008: 126). 
tres y carpinteros del Arbeiter Fraind eran proclives, por su inserción en el movimiento obrero, a aceptar la centralidad de las asociaciones proletarias, o que los jóvenes de la pequeña burguesía tendrían una inclinación espontánea hacia el individualismo? En otro orden, ¿'se vinculan el matiz individualista y la cercanía con el Poalei Tzion? Lo que sí podemos entrever es que la forma en que las dimensiones de clase y étnica atravesaron al anarquismo judío dio lugar a la conformación de dos identidades divergentes. El Arbeiter Fraind parece haber siempre destacado su pertenencia al movimiento obrero y al anarquismo por sobre su carácter judío. Lo sugiere la elección en julio de 1907 del nombre de su periódico, La Vida Obrera, que no fue tomado del grupo inglés sino que parece ser una réplica al diario sionista socialista publicado meses antes, La Vida Judía. El conjunto de sus actividades reseñadas muestran una organización dedicada a intervenir en todos los frentes de la lucha de clases. En las iniciativas del círculo Protest, en cambio, se puede adivinar un énfasis (que aumenta en la medida en que se separan del Arbeiter Fraind y del Idisher Arbeiter Tzentr) en la producción y difusión de literatura en ídish, relegando la propaganda anarquista y la vinculación con el movimiento obrero, en lo que puede considerarse un antecedente del anarco-idishismo. Siguiendo esta línea, la ubicación del grupo Protest respecto del movimiento libertario se asemeja en un sentido a la que tenía el Bund dentro de la socialdemocracia, y la débil delimitación del primero con relación al poaleisionismo podría considerarse un antecedente de la cercanía con el sionismo socialista que caracterizó la trayectoria del segundo.

\section{Bibliografia}

Avni, Haim (1983), Argentina y la historia de la inmigración judia (1810-1950), Buenos Aires: Magnes-AMIA.

Avrich, Paul (2005), The Russian Anarchists [1967], Oakland-Edinburgo: AK Press.

Bilsky, Edgardo J. (1985), La FORA y el movimiento obrero (1900-1910), Buenos Aires: CEAL.

- (s/f) Esbozo de historia del movimiento obrero argentino: desde sus origenes hasta el advenimiento del peronismo, Buenos Aires: Biblos-Fundación Simón Rodríguez.

- (1987), "Etnicidad y clase obrera: la presencia judía en el movimiento obrero argentino", en Ana Epelbaum de Weinstein (dir.), Bibliografia temática sobre judaísmo argentino, vol. 4, tomo 1, Buenos Aires: AMIA.

- (1989) "Etnicidad y clase obrera: la presencia judía en el movimiento obrero argentino", en Estudios Migratorios Latinoamericanos, año IV, n ${ }^{\circ} 11$, abril.

- (1992), "Ethnicité et classe ouvrière: les travailleurs juifs à Buenos Aires (1900-1930)", Le Mouvement Social, $\mathrm{n}^{\circ}$ 159, abril-junio, pp. 39-56. 
Brusilovsky, Hertz (1940), "Los judios en el movimiento obrero argentino", en Triwaks, ob. cit.

Camarero, Hernán (2007), A la conquista de la clase obrera. Los comunistas y el mundo del trabajo en la Argentina, 1920-1935, Buenos Aires: Siglo XXI.

Dujovne, Alejandro (2008), "Cartografia de las publicaciones periódicas judias de izquierda en Argentina, 1900-1953”, Revista del Museo de Antropología, vol. I, $\mathrm{n}^{\circ} 1$, Córdoba.

Epelbaum de Weinstein, Ana (dir.) (1987), Bibliografia temática sobre judaismo argentino, vol. 4, tomo 2, Buenos Aires: AMIA.

Falcón, Ricardo (1984), Los origenes del movimiento obrero (1857-1899), Buenos Aires: CEAL.

- (1986-1987), "Izquierdas, régimen político, cuestión étnica y cuestión social en Argentina (1890-1912)”, en Anuario n 12, Rosario.

Katz, Pinie (1946), Geklibene Shriftn, Buenos Aires: ICUF, vol. V.

- (1980), Páginas selectas, Buenos Aires: ICUF.

Kirstein, Jessica (2009), "Soslayando la ciudadanía: los obreros inmigrantes judíos, la participación política informal y nuevos conceptos de la ciudadanía obrera argentina”, en II Jornadas Internacionales de Investigación y Debate Político y VIII Jornadas de Investigación Histórico Social, Buenos Aires, 9 al 12 de diciembre.

Laubstein, Israel (1997), Bund. Historia del movimiento obrero judio, Buenos Aires: Acervo Cultural.

Lewin, Boleslao (1971), Cómo fue la inmigración judia a la Argentina, Buenos Aires: Plus Ultra.

- (1983) op. cit., 2da ed. ampliada.

Lvovich, Daniel (2003), Nacionalismo y antisemitismo en la Argentina, Buenos Aires: Javier Vergara.

Mirelman, Victor A. (1985), "Jewish Leftist Parties in Argentina during the Early 20th Century”, texto presentado al $9^{\circ}$ Congreso de Estudios Judios, Jerusalén, agosto.

- (1988), En búsqueda de una identidad. Los inmigrantes judios en Buenos Aires, 1890-1930, Buenos Aires: Milá.

Moskovicz, Julio (2011), "El sionismo en Uruguay", disponible en www.jai. com.uy [consultado el 23 de abril de 2015].

Moya, José C. (2004), “The positive side of stereotypes: Jewish anarchists in Early-Twentieth-Century Buenos Aires", Jewish History, $\mathrm{n}^{\circ}$ 18, Kluwer Academic Publishers.

Prager, Leonard (1990), Yiddish Culture in Britain. A Guide, Frankfurt: Peter Lang.

Rawin, Gregorio y Antonio López (2001), "La Asociación Racionalista Judia: anarchismo ed ebraismo in Argentina", en Amedeo Bertolo (comp.), L'anarchico e l'ebreo. Storia di un incontro, Milán: Centro studi libertario di Milano.

Regalsky, Marcos (1940), "Los partidos políticos judíos”, en Triwaks, ob. cit. 
Rivanera Carlés, Federico (1986a), Anarquismo, judaismo y masoneria, Buenos Aires: Instituto de Investigaciones sobre la Cuestión Judia, vol. 2.

- (1986b), El judaísmo y la Semana Trágica, Buenos Aires: Instituto de Investigaciones sobre la Cuestión Judía, vol. 3.

Rocker, Rudolf (1949), En la borrasca (años de destierro), Buenos Aires: Tupac.

- (1952) Revolución y regresión, Buenos Aires: Tupac.

Rollansky, Samuel (1940), "El periodismo, las letras y el teatro judíos en la Argentina”, en Triwaks, ob. cit.

Schers, David (1992), "Inmigrantes y política: los primeros pasos del Partido Sionista Socialista Poalei Sion en la Argentina, 1910-1916", Estudios Interdisciplinarios de América Latina y el Caribe, vol. 3, $\mathrm{n}^{\circ} 2$, Tel Aviv.

Senkman, Leonardo (2006), "Los anarquistas en ídish en el imaginario social de Buenos Aires, 1905-1910", en Perla Sneh (comp.), Buenos Aires Ídish, Buenos Aires: Gobierno de la Ciudad de Buenos Aires.

Schiller, Herman (2006), "La participación de los obreros de habla ídish en los orígenes del movimiento obrero argentino", en Perla Sneh (comp.), Buenos Aires Ídish, Buenos Aires: Gobierno de la Ciudad de Buenos Aires.

Suriano, Juan (2000), "El anarquismo", en Nueva historia argentina, tomo V: Mirta Z. Lobato (dir.), El progreso, la modernización y sus limites, 18801916, Buenos Aires: Sudamericana.

- (2001), Anarquistas. Cultura y politica libertaria en Buenos Aires (18901910), Buenos Aires: Manantial.

Triwaks, Hirsch (dir.) (1940), Cincuenta años de vida judia en la Argentina, Buenos Aires: Talleres Gráficos Julio Glassman.

Wald, Pinie (1955), In gang fun tsaitn, Buenos Aires: s/d.

Weinfeld, Eduardo (dir.) (1948), Enciclopedia judaica castellana, México: EJC, tomo 1.

$$
* * *
$$

Titulo: Anarchism in the Jewish labor movement in Buenos Aires (1905-1909)

Resumen: En este artículo analizaremos la historia de los círculos anarquistas judíos que actuaron en Buenos Aires durante el segundo lustro del siglo XX, tratando de poner de relieve su politica y sus especificidades y contribuyendo a la historización de la corriente clasista e internacionalista.

Palabras clave: anarquismo - judíos - movimiento obrero - inmigración - ídish

Abstract: This article explores the history of the Jewish anarchist groups who acted in Buenos Aires during the first decade of the twentieth century, trying to highlight their policy and their specificities and contributing to the historicizing of the internationalist current (supporter of the class struggle).

Key words: anarchism - Jews - working class - immigration - idish

Recepción: 15 de noviembre de 2015. Aprobación: 20 de febrero de 2016 